\title{
Percepção dos moradores de uma ocupação urbana sobre o 'empoderamento' em saúde
}

\author{
Perception of residents of an urban occupation about 'empowerment' \\ in health
}

Shirley Pereira de Almeida', Lilian Machado Torres', Daniele Aguiar Simim', Patrícia Pinto de Paula ${ }^{2}$, Nathan Mendes Souza ${ }^{3}$

DOI: 10.1590/0103-1104202012504

\begin{abstract}
RESUMO Aglomerados populacionais em ocupações urbanas revelam desigualdades sociais, condições desfavoráveis de habitação e saúde, com impactos negativos na qualidade de vida. Contexto desafiador, dada a relação entre condições de moradia, de vida e de saúde, faz-se essencial a legitimação de direitos e deveres sociais dos indivíduos. Objetivou-se analisar a percepção dos moradores de ocupação urbana sobre 'empoderamento' em saúde. Pesquisa exploratória de abordagem qualitativa sobre a percepção dos moradores da ocupação urbana Eliana Silva II (ES), em Belo Horizonte (MG), acerca do 'empoderamento' em saúde. A coleta de dados ocorreu após aprovação nos Comitês de Ética em Pesquisa. Utilizou-se roteiro semiestruturado de entrevista. A amostra totalizou nove participantes residentes na ocupação, com mais de 18 anos de idade e, pelo menos, um ano de residência. A análise, à luz do referencial de Bardin, evidenciou duas categorias temáticas: Saúde e determinação social: reconhecendo as influências sobre a saúde das pessoas; Protagonizando a própria história: o movimento de luta em busca da garantia dos direitos à saúde. Para que as necessidades dos moradores da ocupação estejam na pauta de prioridade do governo, faz-se necessário mobilizar. A luta para conquista e garantia dos direitos é fundamental.
\end{abstract}

PALAVRAS-CHAVE População urbana. Empoderamento. Determinantes Sociais da Saúde. Saúde pública.

1 Faculdade Ciências Médicas de Minas Gerais (FCMMG) - Belo Horizonte (MG), Brasil. spalmeida2005@yahoo. com.br

2 Pontifícia Universidade Católica de Minas Gerais (PUC Minas), Faculdade de Psicologia - Belo Horizonte (MG), Brasil.

${ }^{3}$ Universidade Federal de Minas Gerais (UFMG), Faculdade de Medicina, Departamento de Clínica Médica - Belo Horizonte (MG), Brasil.

\begin{abstract}
Populations clusters in urban occupations reveal social inequalities, unfavorable housing and health conditions, with negative impacts on quality of life. A challenging context, given the relationship between housing, living and health conditions, it is essential to legitimize the social rights and duties of individuals. The objective of this study was to analyze the perception of urban occupation residents on 'empowerment' in health. Exploratory research with a qualitative approach on the perception of residents of the urban occupation Eliana Silva II (ES), in Belo Horizonte (MG), about 'empowerment' in health. Data collection took place after approval by the Research Ethics Committees. A semi-structured interview script was used. The sample totaled nine participants residing in the occupation, over 18 years of age and at least one year of residence. The analysis, in the light of Bardin's framework, showed two thematic categories: Health and social determination: recognizing the influences on people's health; Starring in history itself: the struggle movement in search of guaranteeing health rights. In order for the needs of occupational residents to be on the government's priority agenda, it is necessary to mobilize. The struggle to conquer and guarantee rights is fundamental.
\end{abstract}

KEYWORDS Urban population. Empowerment. Social Determinants of Health. Public health. 


\section{Introdução}

A urbanização acelerada e intensa afeta bilhões de pessoas no mundo, promove aglomerados populacionais que incluem áreas de ocupações desordenadas, precariedade das moradias e do entorno, além da inexistência de propriedade, situações que impactam negativamente a qualidade de vida ${ }^{1-3}$.

Condições desfavoráveis de habitação e piores indicadores de saúde têm efeito direto sobre as populações vulneráveis ${ }^{4-6}$. Os grupos mais fragilizados em relação à educação e ao status socioeconômico se expõem a condições desfavoráveis de moradia, o que amplia a vulnerabilidade e a iniquidade em saúde 7 . Tal enfrentamento rebaixa o nível de saúde dos indivíduos em comparação à população geral ${ }^{4,8,9}$.

Os assentamentos informais frequentemente situam-se em áreas desconsideradas pela especulação imobiliária e surgem a partir da luta pelo direto de moradia nas cidades, 2,10-12. $O$ contexto desafiador, que se amplia cada vez mais, torna relevante abordar o 'empoderamento' ou empowerment dos residentes desses assentamentos ou ocupações urbanas. 'Empoderamento' apresenta-se como sinônimo de emancipação social ${ }^{13,14} \mathrm{e}$, quando o coletivo é considerado, reflete sua relação com o sentido de comunidade estabelecido entre os integrantes ${ }^{5,15,16}$.

Mais especificamente, o 'empoderamento' em saúde refere-se ao processo que permite aos indivíduos maior controle sobre as decisões que afetam sua vida e saúde ${ }^{\mathbf{1 4 , 1 7}}$. A partir da visão crítica de sua realidade social, das influências sobre a própria saúde e da condição de vida, tornam-se protagonistas da própria história, ao transformar essa realidade na busca por melhor qualidade de vida ${ }^{\mathbf{1 8}}$.

Devido ao aumento das populações em ocupações urbanas, à importância dos espaços ocupados, à relação entre condições de moradia e de vida e o processo saúde-doença, fazem-se essenciais a construção e a legitimação de direitos e deveres sociais dos indivíduos, principalmente no que tange à saúde.
Assim, torna-se relevante discutir 'empoderamento' em saúde no contexto das ocupações urbanas, especialmente no que se refere às condições disponíveis, aos desafios e ao potencial de enfrentamento voltados à superação dos problemas cotidianos. O objetivo do estudo foi analisar a percepção dos moradores de uma ocupação urbana sobre ‘empoderamento’ em saúde.

\section{Material e métodos}

Pesquisa exploratória de abordagem qualitativa sobre a percepção dos moradores da ocupação urbana Eliana Silva II (ES), em Belo Horizonte (MG), sobre o 'empoderamento' em saúde. Tal abordagem considera a relação dinâmica entre o mundo real e o indivíduo, com ênfase na subjetividade, que não se traduz em números ${ }^{19,20}$.

A primeira tentativa de ocupação do referido espaço ocorreu em 2012 com, aproximadamente, 200 famílias, porém, houve ação de reintegração de posse. No mesmo ano, a segunda tentativa ocorreu em área próxima, em um terreno público. Em 2016, residiam nessa ocupação cerca de 350 famílias²1.

Os participantes do estudo foram os moradores da ocupação, maiores de 18 anos de idade e, pelo menos, com um ano de residência no local. A definição prévia do tempo de moradia justifica-se pela necessidade de o morador ter vivenciado parte da história da ocupação ES. A seleção dos participantes foi intencional, a partir da estratégia de 'bola-de-neve' ou em 'série'20. O estudo atendeu às diretrizes da Resolução $n^{\circ} 466 / 12^{22}$, que trata dos aspectos éticos das pesquisas com seres humanos. A coleta de dados ocorreu entre outubro e dezembro de 2015, após aprovação no Comitê de Ética em Pesquisa da Faculdade Ciências Médicas de Minas Gerais (Parecer n ${ }^{0}$ 558.222/ 2015).

Após a aproximação dos pesquisadores com os moradores, ocorreram as explicações necessárias e procedeu-se à assinatura de Termo de Consentimento Livre e Esclarecido pelos indivíduos que assentiram 
participar. Em seguida, foram realizadas entrevistas individuais, que duraram 30 minutos, em média, efetivadas na ocupação ES, em espaço designado pelos moradores para preservar a sua privacidade. $\mathrm{O}$ sigilo foi assegurado em todas as etapas do estudo, mediante a identificação dos participantes por código alfanumérico.

O critério utilizado para não inclusão de novos participantes deveu-se à saturação de dados, quando o conteúdo significativo se tornou repetitivo. As entrevistas foram transcritas por um dos pesquisadores e lidas por todos os envolvidos, de forma individual e em grupo, para identificar a convergência dos depoimentos e possibilitar a apreciação e a categorização, a partir da técnica de análise de conteúdo ${ }^{23}$. Esse processo permitiu a organização das ideias, o agrupamento de expressões com o mesmo sentido e a sistematização da apresentação dos dados subjetivos em várias subcategorias que foram reagrupadas, após conclusão da análise.

\section{Resultados}

Nove participantes foram entrevistados, sendo cinco mulheres (55\%). Do total, $67 \%$ possuíam ensino fundamental completo ou incompleto, e todos residiam na ocupação desde sua criação, em 2012. A análise do conteúdo dos depoimentos evidenciou duas categorias temáticas, quais sejam: 'Saúde e determinação social: reconhecendo as influências sobre a saúde das pessoas' e 'Protagonizando a própria história: o movimento de luta em busca da garantia dos direitos à saúde'.

\section{Saúde e determinação social: reconhecendo as influências sobre a saúde das pessoas}

Os participantes concebem saúde como direito social, necessidade para a vida e sensação de bem-estar que se relacionam com a dinâmica social e implicações para a vida:
Saúde é bem-estar do corpo, da mente, bem-estar social. Harmonia é saúde. (M-1).

Saúde é tudo. Tem que ter saúde porque lá em casa eu sou o pilar. Tenho que ter saúde. (M-6).

Eu acho que saúde é garantia de direitos, como no caso da moradia. (M-7).

Também identificam aspectos do cotidiano que influenciam o processo saúde-doença, como as precárias condições de vida, moradia, infraestrutura, saneamento básico, energia elétrica, alimentação, renda e transporte:

Saúde é rede de esgoto, água e asfalto, porque as ruas são de terra. É coleta de lixo que não temos aqui. Muito lixo jogado: garrafa reciclável e saco plástico que acumulam água e sujeira. (M-5).

Na ocupação urbana sofremos todas as repressões [...] falta de comida, de alimento, de banheiro e de água. (M-1).

O transporte público é importante. Aumento de passagem, está tudo precário e não tem um coletivo de qualidade. (M-9).

A dificuldade de acesso a serviços essenciais, como os de saúde e educação, foi apontada como fundamental à saúde dos participantes e de suas famílias:

Hoje o sistema de vida que levamos interfere na saúde. As condições são péssimas, sem apoio algum, sem assistência de nada, de posto de saúde, de escola. (M-2).

A iniquidade no atendimento aos moradores e a precariedade dos serviços de saúde, que dificultam o acesso dessa população, foram citados:

Nós, como ocupação urbana, não temos atendimento específico. Acho necessário atenção diferenciada por não termos saneamento básico, esgotamento sanitário decente. (M-1). 
[...] para fazer uma consulta simples ou um exame, demora um ano, uma cirurgia é preciso um ano e meio para se conseguir... E temos profissionais capacitados e estrutura no País. Então, por que não funciona? (M-7).

Na visão dos moradores, a falta de comprovante de endereço e o preconceito por residirem em uma ocupação constituem barreiras de acesso aos serviços de saúde:

Chegamos nos centros de saúde ou em órgãos públicos e não temos o comprovante de endereço. É mais complicado. O sistema traz mais dificuldade ainda do acesso. (M-2).

Já sofremos preconceito por vivermos em uma ocupação urbana. Sofremos mais do que as pessoas que moram em lotes urbanizados. Somos muito mais discriminados. (M-1).

Apesar do acesso limitado ao Sistema Único de Saúde (SUS), a maioria dos entrevistados identificou a Unidade Básica de Saúde (UBS) e a Unidade de Pronto Atendimento (UPA) como locais para o cuidado com a saúde:

Nós buscamos diálogo no posto de saúde para conseguir atendimento. Em relação à saúde, aqui na ocupação, o posto de saúde é melhor do que a UPA. (M-3).

Dentre as ações de saúde desenvolvidas pela UBS, foram destacados o cadastramento, para acesso à UBS, e a vacinação:

Depois de algum tempo morando aqui, a equipe de saúde veio com o posto de saúde, e, depois de três meses, nós fomos fazer o cadastramento para o direito à assistência no posto [...]. Vieram algumas vezes vacinar, atualizar o cartão, mas só isso. (M-1).

Citaram também a contribuição das universidades, por meio das ligas acadêmicas, que prestam apoio aos moradores da ocupação:
[...] tem que agradecer à Universidade, por meio de cada estudante que esteve aqui, de enfermagem, engenharia, medicina, psicologia e de serviço social. Todos contribuem. A política tem deixado a desejar, mas graças aos estudantes, eles têm suprido o que o Estado não tem feito. (M-4).

As parcerias que se desenvolvem com as Universidades são importantes [...] os estudantes dão uma noção maior sobre o significado do SUS e da própria saúde. Dicas importantíssimas para se alcançar qualidade de vida. Isso é parte na luta de resistência para uma condição melhor. [...] na parte da prevenção, por exemplo, tem parcerias para debates, seminários, atividades de conscientização sobre vários temas e saúde é um deles [...]. (M-7).

O ambiente em que vivem na ES foi destacado como determinante do adoecimento ou da condição precária de saúde, sendo responsabilidade de todos o cuidado com o meio:

Sobre a dengue, a gente cuida do terreno, e o vizinho não. Não adianta eu querer manter a minha saúde correta e o meu vizinho não. (M-6).

Cuidamos de uma nascente aqui na ocupação. [...] porque tinha uma fábrica aqui perto que poluía. Nós denunciamos e parou, acabou o mau cheiro, o calor. (M-9).

O dever do Estado em prover os serviços essenciais, a necessidade de uma consciência política dos gestores quanto à destinação de recursos financeiros necessários para a manutenção e qualidade desses serviços, bem como a influência da crise econômica, foram descritos como fatores que impactam negativamente a saúde das pessoas:

A nossa saúde já está defasada e, pela crise econômica do País, tende a piorar. O Estado tem deixado a desejar e vai continuar assim, porque, infelizmente, ele afirma que não tem dinheiro. (M-4).

Moradores da ES valorizam o SUS, mas destacam a sua precariedade devido ao subfinanciamento da saúde, ao desvio dos recursos 
financeiros, à má gestão e a não priorização de ações necessárias:

E o conjunto de todos os outros direitos que também são negados ao povo, boa parte deles seria fundamental para a saúde. O SUS é uma criação para o povo, os trabalhadores, em especial, mas, o investimento é muito limitado. E não é só o problema de gestão. Ao invés do dinheiro que vai para os banqueiros, para os patrões, por meio da dívida pública, fosse investido massivamente em saúde, muitas vidas seriam preservadas. (M-7).

Para os indivíduos, a falta de reconhecimento da ocupação ES, pelo Estado, dificulta o investimento na melhoria da infraestrutura da área ocupada:

A ocupação, infelizmente, o Estado não reconhece. Ele não vê obrigações para com os moradores. Enquanto não houver esse reconhecimento, por parte do Estado, não haverá melhoria para a comunidade. (M-4).

Na percepção dos moradores, ocupar e construir em terrenos ociosos possibilitaram a aquisição de moradias e a percepção de contribuir para o município, que não precisaria despender recursos para tal fim:

[...] a construção de casas na comunidade, em terreno abandonado, evitou que o prefeito tivesse que construir casas. Esse dinheiro era, por exemplo, das famílias que moravam de aluguel e de favor ou que estavam na lista de espera do programa Minha Casa Minha Vida. Então, hoje eles têm uma casa. O que nós precisamos é da boa vontade do prefeito para legalizar os bairros, porque ocupamos terreno vazio, que não servia para nada. (M-9).

Os entrevistados identificam sua condição enquanto moradores da ocupação ES em relação aos Determinantes Sociais da Saúde (DSS). A partir dessa compreensão, empreendem estratégias de enfrentamento e de superação dos desafios, mediante mobilizações, descritas a seguir.

\section{Protagonizando a própria história: o movimento de luta em busca da garantia dos direitos à saúde}

A conquista de melhores condições de vida e saúde é fruto da mobilização e da luta dos moradores da ocupação pela garantia de seus direitos:

Com a luta da comunidade é que conseguimos o direito de ter a água canalizada e o esgoto. E foi adquirido na justiça ficar com o 'gato' da água e da luz, até ser legalizado. (M-4).

Dezenas de coisas poderiam melhorar a nossa qualidade de vida e saúde. Temos que lutar, reivindicar e mobilizar. Nos últimos meses pressionamos para o Posto de Saúde atender todos os moradores. (M-7).

Para os participantes, o movimento da comunidade significa, também, a corresponsabilização pelo cuidado com o meio ambiente:

Costumamos fazer assembleias para manter a limpeza da rua, o esgoto 'bonitinho', não deixar entupir, fazer direito a ligação de água de chuveiro para não correr na rua a céu aberto. Isso ajuda muito. (M-6).

Apesar da precariedade das condições em que vivem e das dificuldades que enfrentam, os moradores buscam superá-las com o apoio mútuo e percebem que o movimento e as conquistas impulsionam o coletivo a seguir em frente:

[...] as condições que temos são boas porque não nos incomodamos com as dificuldades. Sabemos que temos direitos e estamos na luta pela sua garantia. (M-2).

Eu tenho que agradecer ao movimento MLB [referindo-se ao Movimento de Luta nos Bairros, 
Vilas e Favelas, com informações disponíveis no site www.mlbbrasil.org], porque consegui a minha moradia. Não é o ideal, mas não troco por nada. Ea cada dia vai melhorar. Vejo essa ocupação como exemplo para muitos lugares. Acredito que quando estivermos bem, com o título de posse e com o esgoto, as pessoas sempre vão se lembrar da ocupação ES e vão ter forças para lutar. (M-4).

Dois participantes ressaltam os meios de comunicação como recurso importante para divulgar os direitos dos cidadãos e como estratégia de luta para garanti-los:

Os meios de comunicação deveriam ser mais abertos para mostrar às pessoas os seus direitos. $(\mathrm{M}-2)$.

Muitas vezes, quando não tem médico na UPA, chamamos a imprensa e rapidinho aparece médico e remédio. Sem luta nada acontece. (M-9).

Os participantes enfatizam que a união de todos em um movimento em prol de um bem comum é fundamental para a conquista:

Mesmo nas dificuldades, tentamos ser unidos para lutar por melhores condições de vida na comunidade. A maior parte das coisas que temos, como a creche, as ruas e o esgoto ecológico, foram criados e financiados por nós. Não temos o apoio do prefeito e fazemos em conjunto. (M-8).

Um dos moradores afirma que a luta pelos direitos representa disputa e relação de poder entre as classes, entre os cidadãos e o Estado. Destaca a necessidade de mobilização e participação social para garantir que governos cumpram seu dever:

Participamos de uma campanha, desde o final do ano, para aumentar o investimento, ao invés de cortes no orçamento. Cortar dinheiro dos banqueiros e garantir mais recursos para saúde e educação [...]. É uma disputa na sociedade e consideramos que participar da luta do lado da classe trabalhadora é necessário para mudar as coisas, além de saúde melhor, não só para os moradores da ocupação, mas para o povo brasileiro. [...]. É obrigação do Estado e ele tem que priorizar. É possível resolver o problema. Mas, é preciso prioridade e aí entram a mobilização e as lutas para mudar o sistema, a situação. (M-7).

Alguns depoentes relacionaram a situação macroeconômica atual ao pagamento das dívidas públicas. Apontaram também a importância da representatividade política de comunidades mais vulneráveis e marginalizadas para a garantia de seus direitos:

Paga-se imposto no País e não é pouco. Quanto mais pobre, mais imposto se paga. Um mês de pagamento da dívida pública é mais do que é investido na saúde e educação, no ano todo. (M-7).

Se tivéssemos um partido que dialogasse com a classe trabalhadora e com os movimentos, não seria esse caos. Temos que criar um partido nascido nas ocupações e no movimento de luta. Seria uma opção para discutir e lutar na Câmara dos Deputados. Ter um partido legal, que defenda a nossa luta significa melhorias. (M-9).

Observou-se que as conquistas dos moradores da ocupação ES coroam o 'empoderamento' e a coesão social de seus membros. A melhoria das condições de vida adveio da construção de ruas, esgotamento sanitário e de creche, pela resiliência, articulação e participação de todos, no movimento, bem como pelo espírito de união entre eles em prol de um objetivo comum.

\section{Discussão}

Foi possível reforçar a relação estabelecida entre as condições de vida e saúde e o conceito de saúde proposto pela Organização Mundial da Saúde (OMS). Trata-se de um bem essencial à vida $^{24}$, discutido na VIII Conferência Nacional de Saúde ${ }^{25}$ e na I Conferência Internacional de Promoção da Saúde ${ }^{24}$. Segundo a OMS, os DSS referem-se a aspectos sociais a que 
todos estão sujeitos, desde o nascimento até a velhice, que consideram o modo de vida e de trabalho, além dos sistemas disponíveis para lidar com a doença. Os pré-requisitos para a melhoria das condições de saúde incluem paz, habitação, educação, alimentação, renda, ecossistema saudável, solidariedade, democracia, cidadania, participação e ação conjunta, justiça social e equidade24,26; e essa inter-relação entre as condições e modos de vida e saúde, mediante a vulnerabilidade social, tem sido amplamente apontada ${ }^{5,27,28}$. Tal entendimento foi evidenciado nos resultados pela percepção dos moradores de que se trata de um direito e do bem-estar social que concorrem para o alcance dos demais direitos reconhecidos.

Os depoimentos relacionam alguns DSS ao processo saúde-adoecimento-cuidado, a partir da reflexão sobre as condições de vida na ocupação ES, em um contexto de significativas iniquidades e injustiças sociais, e que tem sido a realidade vivenciada por moradores de áreas de assentamentos informais ${ }^{\mathbf{6 , 2 7 , 2 9 - 3 2}}$. Evidencia-se o entendimento do processo saúde-doença enquanto um fenômeno social, fruto da inter-relação do homem com o meio ambiente e com o território ocupado. Soma-se, outrossim, sua relação com outras pessoas em um contexto econômico, cultural e político, ou seja, na perspectiva da determinação social da vida e, não apenas, da determinação social da saúde 6,28,32-34. Os resultados apontaram que é real o reconhecimento das precárias condições do espaço habitado que incluem saneamento básico, energia elétrica, alimentação, renda e transporte. Há o entendimento de que a falta de legalização territorial dificulta o investimento nas melhorias estruturais almejadas que equivalem à saúde e ao bem-estar.

Os entrevistados destacaram as principais dificuldades relacionadas com o acesso aos serviços e ações de saúde, como, por exemplo, a exigência de comprovante de endereço, o preconceito e discriminação, além da falta de recursos humanos e de infraestrutura da UBS e da UPA, indicadas como referência para ES e toda a população adscrita. A despeito das distintas significações, ou não, de acesso e acessibilidade em saúde, observa-se o uso do termo acessibilidade para as características da oferta de serviços e ações de saúde, sendo o acesso a forma como as pessoas percebem a acessibilidade $^{35}$. Entretanto, considera-se que ambos os termos podem significar tanto a capacidade em se obter cuidados de saúde quanto a capacidade dos serviços em responder às necessidades de uma determinada população $0^{36}$.

Os moradores da ocupação ES destacaram algumas das ações desenvolvidas pelos agentes de endemias, eventuais programas educativos, seminários e palestras. Afirmam possuir outras informações sobre os serviços de saúde disponíveis e próximos à ocupação, porém, denunciam limitação no acesso, por não reconhecimento do espaço ocupado, o que dificulta o cadastramento, além dos problemas na infraestrutura. Ademais, sabe-se que a aceitabilidade do serviço, por parte de moradores, relaciona-se às próprias barreiras ao acesso, à falta de recursos humanos, insumos e equipamentos e à precária infraestrutura ${ }^{27,29}$. A questão do espaço físico e a busca incessante de melhorias emergiram nos depoimentos desde os relatos sobre o ato de ocupação inicialmente com 200 famílias e, depois de quatro meses da expulsão das famílias, com o incremento de 350 famílias aproximadamente - até os dias atuais.

Além das desigualdades socioeconômicas para o acesso à saúde, as barreiras impostas pelo sistema, tanto estruturais quanto de organização dos serviços, limitam o atendimento às necessidades e reforçam as desigualdades sociais $^{37-39}$. De fato, o acesso aos serviços para determinadas ações condiciona-se ao cadastramento das pessoas residentes no território da UBS. As concepções de território e territorialização em saúde surgiram com a descentralização e municipalização das ações pelo SUS e são utilizadas, respectivamente, como locus e ferramenta de vigilância em saúde. A territorialização, no âmbito da Atenção Primária à Saúde (APS), descentraliza ações e serviços e integra a vigilância para o 
controle dos determinantes, dos riscos e dos danos à saúde das populações em seus territórios, como uma ação de responsabilidade sanitária da APS ${ }^{40-44}$. Especificamente, no cenário do estudo, foi reconhecida a falta de equidade no atendimento aos moradores, pois o entendimento na ocupação é que, diante da precariedade das condições de vida e da vulnerabilidade, deveria haver maior atenção, atendimentos diferenciados e especializados.

As ações realizadas pelos profissionais da UBS na ocupação, como cadastramento, imunização e combate à dengue, respondem por parte das necessidades dos moradores, fato que evidencia conhecimento sobre seus direitos, além de motivar a mobilização por sua ampliação. Ademais, intervenções comunitárias e em visitas domiciliares podem mitigar os DSS mediante o 'empoderamento' de pessoas mais vulneráveis, sobretudo referente à prevenção de doenças na atenção primária ${ }^{45}$. Nesse ínterim, evidenciou-se, na ocupação ES, a atuação de escolas de engenharia, medicina, enfermagem, psicologia e serviço social, principalmente para a educação para a saúde. Os participantes valorizam a atuação de instituições de ensino e percebem o suprimento parcial de lacunas deixadas por diversos setores públicos. Pesquisas recentes descrevem essa integração academia-ocupações urbanas-movimentos sociais como elemento promotor de construção mútua de saberes que estimulam a construção de cidadania, além de contribuírem para o enfrentamento dos DSS $\mathbf{5 , 2 7 , 4 6}$. Práticas educativas associadas a movimentos sociais, a partir da educação popular em saúde, contribuem para o protagonismo e o controle social e para a participação popular no SUS, ampliam os conhecimentos sobre a saúde pública e a articulação dos movimentos sociais em luta pelos direitos universais, os quais incluem a saúde ${ }^{\mathbf{4 7}}$.

A responsabilidade coletiva no cuidado com o meio ambiente foi destacada pelos participantes como determinante do adoecimento ou condição de saúde na ocupação ES. Há que se ressaltar que tal consciência e sua relação com a saúde resultam da organização comunitária e do processo de 'empoderamento' coletivo, a partir da educação popular em saúde, da troca de conhecimentos e saberes, de discussões e das ações voltadas para um objetivo comum ${ }^{18,33}$.

Ao se considerar que a ocupação, no presente estudo, está em uma área de nascente de água e de preservação ambiental, percebe-se a preocupação de todos no tocante à preservação da mata ciliar. Os moradores ressaltaram o papel dos líderes nas assembleias ao enfatizar que a limpeza dos lotes beneficia a todos e garante bem-estar e qualidade de vida. De fato, o processo de ocupação de terrenos em localidades de preservação ambiental ou em margens de rios e córregos pode representar um conflito socioambiental48. As habitações irregulares podem significar maior exposição a riscos químicos, físicos e biológicos, além da falta de saneamento básico, da instabilidade do terreno e do alto índice de violência $6,46,49,50$.

Assim, o direito à habitação, como fator de desenvolvimento humano e social, não deve ser visto apenas como um espaço físico para viver, pois uma moradia adequada requer acessibilidade, equipamentos comunitários, mobilidade urbana, saneamento e segurança, entre outros ${ }^{6,27,49}$. Na ausência dos determinantes, a saúde é prejudicada ${ }^{6,49}$. Em função disso, os mutirões de limpeza são atividades de cuidado na ocupação ES, cuidado com o espaço, com o ambiente e com os moradores, a partir das reuniões e decisões coletivas.

Sabe-se que o cenário da ocupação impacta a saúde das pessoas que se tornam mais vulneráveis, devido ao risco social imposto pelos motivos que as levaram a viver em tais locais. Detectou-se influência das concepções dos direitos humanos no que se refere a grupos ou indivíduos fragilizados, jurídica ou politicamente, enquanto cidadãos, e que se transformam em indicador de iniquidade e desigualdade social ${ }^{51,52}$. Urge a implementação de ações por parte dos serviços de saúde que identifiquem os riscos e as vulnerabilidades a que estão expostas essas comunidades ${ }^{5,52}$, como evidenciado nos resultados. 
Outro aspecto identificado foi o preconceito e a discriminação sofridos pelas pessoas que moram em áreas ocupadas, desde a falta de comprovação de endereço até a burocracia dos serviços durante o atendimento prestado, situações que dificultam o acesso. Os relatos de sofrimento no cenário estudado para além da doença que motivou a busca pelo serviço, em função da ausência de endereço, evidenciam a certeza das desigualdades sociais. A situação descrita pode ser definida como contexto de segregação, haja vista as condições de 'ilegalidade' por se viver em uma ocupação urbana ${ }^{5,51-53}$. Por meio da exclusão social e da criminalização da pobreza, as populações das periferias são penalizadas, culpabilizadas, desqualificadas e estigmatizadas, o que restringe e limita o seu acesso aos serviços públicos. Soma-se a isso o discurso, denominado senso comum, que utiliza adjetivos como 'invasores', 'preguiçosos' e 'sem vontade' que torna os indivíduos invisíveis e marginalizados pela sociedade e pelo Estado 2,5,27,53.

A insuficiente presença do poder público na ocupação urbana ES é percebida pelos moradores, pois conhecem o papel do Estado na prestação de serviços essenciais e na construção de obras de infraestrutura necessárias. $\mathrm{Na}$ ocupação, tal 'empoderamento’ é representado pelo reconhecimento desse elemento como dificultador para o acesso a saneamento básico, coleta de lixo, ruas asfaltadas e moradia digna; e a literatura sobre comunidades vulneráveis corrobora os achados $\mathbf{5}^{\mathbf{1 8}, \mathbf{4 6}, \mathbf{5 2}}$. Ademais, os participantes mencionam a falta de consciência dos políticos e gestores públicos, a inexistência de vontade política e de gestão pública eficiente para resolver os problemas de saúde da população. Destacam a insuficiência ou, ainda, a não destinação adequada dos recursos financeiros necessários.

Os moradores da ES protagonizam a própria história, reconhecem a importância, mas denunciam as dificuldades em relação ao SUS nas oportunidades de luta em busca de garantia dos direitos à saúde. Além disso, o engajamento aos movimentos sociais organizados eleva o conhecimento sobre direitos, estratégias de luta e formação política ${ }^{\mathbf{1 1 4 6}}$. Os resultados apontam uma conscientização crítica referente à origem dos problemas e estratégias de enfrentamento em assembleias, palestras e rodas de conversa realizadas na ocupação. A luta pelo acesso à água canalizada, à rede de esgoto e luz, à saúde e à educação infantil é exemplo de mobilizações que representaram algum sucesso. Estudos defendem que a participação popular, a força, a articulação e a organização diante de situações de vulnerabilidades fazem emergir o 'empoderamento' dessas comunidades ${ }^{\mathbf{5} 27,52}$. Os participantes da ES ainda ressaltam os encaminhamentos para $o$ atendimento a todos os moradores na UBS e para a presença de profissionais médicos e de insumos, o que demonstra o reconhecimento de sua força para o resultado desejado.

De fato, movimentos sociais no Brasil têm surgido com o processo de redemocratização, em diferentes formas de luta, a partir da consciência quanto à precariedade das situações vivenciadas pelo coletivo, ao compartilhamento das experiências, ao sentimento de pertencimento e à necessidade de melhores condições de vida5,11,27,46, o que pode ser evidenciado nos depoimentos dos moradores da ocupação ES que esperam dias melhores, a partir do título de posse da moradia, com serviços básicos de água, luz e esgoto.

No contexto dos movimentos pelo direito à saúde, torna-se importante compreender que, no processo saúde-doença, os DSS e as soluções para os problemas devem ser pensados coletivamente ${ }^{54}$. No presente estudo, percebe-se o 'empoderamento' de lideranças do movimento, aumento da criticidade e da coesão social em torno de objetivos comuns, como, por exemplo, participar das lutas, modificar as condições ainda precárias e, até mesmo, mudar a situação de desigualdade do País. Reconhece-se que a organização dessas ocupações se distingue de outros movimentos sociais quando busca romper com o princípio de 'cada um por si' e construir uma experiência coletiva de interdependência, cooperação e 
*Orcid (Open Researcher and Contributor ID). corresponsabilização de êxitos e fracassos. A presença de lideranças fortes contribui para direcionar ações comuns ${ }^{27,53}$. Na ocupação ES, uma das primeiras ocupações que ocorreram em Minas Gerais ${ }^{27}$, destaca-se a compreensão de que a união de todos é fundamental para a conquista do bem comum, resultado dos movimentos sociais em busca por moradia digna e direito à habitação. $O$ processo de formação da ocupação desde o início, sua trajetória de luta, suas dificuldades e a forma de organização em equipes, com definições de papéis, representam um exemplo bem-sucedido de gestão coletiva.

Nesse contexto, o 'empoderamento' impulsiona grupos e comunidades para o crescimento e a autonomia, a partir de ações que visam à consecução de objetivos definidos coletivamente 5,13,16,17,55. O 'empoderamento' comunitário envolve capacitação de grupos ou indivíduos desfavorecidos para a articulação de interesses, conquista dos direitos de cidadania, defesa de seus interesses e influência nas ações do Estado ${ }^{13,16,55}$. Há graus diferentes de liberdade dos indivíduos e comunidades na tomada de decisões para melhores condições de vida e saúde, a partir da cooperação e participação social ${ }^{5,55,56}$. Nos depoimentos dos moradores da ocupação ES, foi possível identificar que eles reconhecem seus direitos de habitação, qualidade de vida e atenção à saúde, mas lutam para conquistá-los ou ampliá-los; e, apesar das dificuldades, as conquistas são um incentivo para continuar a luta coletiva pelo bem comum. A resiliência ou a capacidade de adaptação para enfrentar e superar as dificuldades está presente ao acreditarem e esperarem a modificação do cenário em que vivem. Evidenciou-se que os moradores da ES consideram o coletivo e refletem o significado de comunidade, contido na própria definição do 'empoderamento'5,15,16. No contexto de comunidades marginalizadas e vulneráveis, pode ser entendido como um movimento para ir adiante, mesmo diante de impasses e adversidades ${ }^{52,55,57}$.

Detecta-se, portanto, o 'empoderamento' dos moradores da ocupação ES, protagonistas de sua própria história, por meio da percepção sobre suas condições de saúde, assim como pela identificação dos desafios e estratégias de superação, além da visão mais ampliada sobre os caminhos necessários para uma situação mais justa e igualitária para todos.

\section{Conclusões}

A luta para conquistar e garantir os direitos é fundamental para pressionar o Estado a cumprir o seu papel previsto em lei e de gerir os recursos públicos, ao priorizar o que é essencial. No entanto, para que as necessidades dos moradores da ocupação ES estejam na pauta de prioridade do governo, faz-se necessária a mobilização dos moradores. A sua percepção é crítica e oscila entre o reconhecimento da saúde como direito - no qual se inclui a moradia e todos os demais componentes da vida - e os meios de sobrevivência e acesso aos serviços públicos de saúde, educação, segurança, transporte e lazer, entre outros, apesar de falhas reconhecidas. $\mathrm{O}$ 'empoderamento' se dá, portanto, e não apenas no que se refere à saúde, quando os indivíduos são um coletivo, tomam para si o controle sobre as decisões que afetam sua vida e saúde; e este, por sua vez, terá alcance político quando em conectividade com outros grupos. Entretanto, é preciso considerar que novos estudos devem abordar outros problemas vivenciados e formas de enfrentamento, além das questões relativas a gênero, etnias, renda e intersetorialidade.

\section{Colaboradores}

Almeida SP (0000-0003-3236-3095)*, Torres LM (0000-0002-7510-7078)*, Simim DA (0000-0003-4022-7173)*, Paula PP (00000002-5340-8769)* e Souza NM (0000-00024341-1964)* contribuíram igualmente para a elaboração do manuscrito. 


\section{Referências}

1. Scheuer S, Haase D, Volk M. On the Nexus of the Spatial Dynamics of Global Urbanization and the Age of the City. PLoS ONE [internet]. 2016 [acesso em 2018 out 14]; 11(8). Disponível em: https://journals.plos.org/ plosone/article?id=10.1371/journal.pone.0160471

2. Morais MP, Krause C, Lima Neto VC. Caracterização e tipologia de assentamentos precários: estudos de caso brasileiros. Brasília, DF: IPEA [internet]; 2016. [acesso em 2018 nov 22]. Disponível em: http:// www.ipea.gov.br/portal/index.php?option=com content $\&$ view $=$ article $\& i d=28182$.

3. Aliyu AA, Amadu L. Urbanization, cities, and health: The challenges to Nigeria - a review. Ann Afr Med [internet]. 2017 [acesso em 2018 nov 22]; 16(4):149158. Disponível em: http://www.annalsafrmed.org/ text.asp?2017/16/4/149/216708.

4. Thomson H, Thomas S, Sellstrom E, et al. Housing improvements for health and associated socio-economic outcomes. Cochrane Database Syst Rev [internet]. 2013 Fev [acesso em 2018 nov 22]; (2):CD008657. Disponível em: https://www.ncbi.nlm.nih.gov/pubmed/23450585.

5. Sousa IV, Brasil CCP, Silva RM, et al. Diagnóstico participativo para identificação de problemas de saúde em comunidade em situação de vulnerabilidade social. Ciênc. Saúde Colet. 2017; 22(12):3945-54.

6. Costa TA. Cidade ignorada: um retrato da universalização do saneamento em assentamentos precários no entorno da Billings e Guarapiranga [tese]. São Paulo: Faculdade de Saúde Pública; 2017.

7. Roy M, Généreux M, Laverdière E, et al. Surveillance of Social and Geographic Inequalities in Housing-Related Issues: the Case of the Eastern Townships, Quebec (Canada). Int. J. Environ. Res Public Health [internet]. 2014 [acesso em 2018 nov 22]; 11(5):482544. Disponível em: https://www.ncbi.nlm.nih.gov/ pubmed/24806192.
8. Novoa AM, Ward J, Malmuse D, et al. How substandard dwellings and housing affordability problems are associated with poor health in a vulnerable population during the economic recession of the late 2000s. Int J Equity Health [internet]. 2015 Nov [acesso em 2018 nov 22]; 14:120. Disponível em: https:// www.ncbi.nlm.nih.gov/pmc/articles/PMC4632653/.

9. Seneviratne R, Gunawardena NS. Prevalence and associated factors of wheezing illnesses of children aged three to five years living in under-served settlements of the Colombo Municipal Council in Sri Lanka: a cross-sectional study. BMC Public Health [internet]. 2018 [acesso em 2018 nov 22]; 18(1):127. Disponível em: https://www.ncbi.nlm.nih.gov/pubmed/29325544.

10. Sarmento HBM, Cortizo MDC. Espaço e desigualdade. Revista Katálysis [internet]. 2016 [acesso em 2018 nov 22]; 19(2):224-231. Disponível em: https:// dx.doi.org/10.1590/1414-49802016.00200007.

11. Guimarães MCR. Os movimentos sociais e a luta pelo direito à cidade no Brasil contemporâneo. Serv Soc Soc. $2015 ; 124: 721-745$.

12. Carleial L. Moradia digna: direito conquistado, mas ainda não implementado. In: Morais MP, Krause C, Lima Neto VC, editores. Caracterização e tipologia de assentamentos precários: estudos de caso brasileiros. Brasília, DF: Ipea [internet]; 2016. [acesso em 2018 nov 22]. p. 15-19. Disponível em: http:// www.ipea.gov.br/portal/index.php?option=com_ content\&view $=$ article\&id $=28182$.

13. Baquero RVA. 'Empoderamento': Instrumento de emancipação social? Uma discussão conceitual. Rev Debates [internet]. 2012 [acesso em 2018 nov 22]; 6(1)173-187. Disponível em: http://seer.ufrgs.br/debates/article/view/26722.

14. Souza JM, Tholl AD, Córdova FP, et al. Aplicabilidade prática do ‘empoderamento' nas estratégias de promoção da saúde. Ciênc. Saúde Colet. [internet]. 
2014 [acesso em 2018 nov 22]; 19(7):2265-76. Disponível em: http://www.scielo.br/scielo.php?script=sci arttext\&pid=S1413-81232014000702265.

15. Ahmad MS, Talib NB. Analysis of Community Empowerment on Projects Sustainability: Moderating Role of Sense of Community. Soc Indic Res [internet]. 2016 [acesso em 2018 nov 22]; 129(3):1039-1056. Disponível em: https://www.researchgate.net/publication/284824958.

16. Silverman RM. Community development for equity and empowerment. Societies [internet]. 2018 [acesso em 2018 dez 19]; 8(4):119. Disponível em: https:// www.mdpi.com/2075-4698/8/4/119/htm.

17. Fung CSC, Yu EYT, Guo VY, et al. Development of a Health Empowerment Programme to improve the health of working poor families: protocol for a prospective cohort study in Hong Kong. BMJ Open [internet]. 2016 [acesso em $2018 \mathrm{dez}$ 19]; 6(2):e010015. Disponível em: https://www.ncbi.nlm.nih.gov/pmc/ articles/PMC4746471.

18. Rückert B, Aranha AVS. Lutar por saúde é lutar por reforma agrária: estudo sobre práticas de saúde no Movimento dos Trabalhadores Rurais Sem Terra. Saúde Soc [internet]. 2018 [acesso em 2018 nov 30]; 27(1):116-127. Disponível em: http://www. scielo.br/scielo.php?script=sci_arttext\&pid=S0104$-12902018000100116 \& \operatorname{lng}=\mathrm{en} \& \mathrm{nrm}=\mathrm{iso}$.

19. Minayo MCS. O desafio do conhecimento: pesquisa qualitativa e saúde. São Paulo: Hucitec; 2014.

20. Moreira H, Caleffe LG. Metodologia da pesquisa para o professor pesquisador. Rio de janeiro: DP\&A; 2006.

21. Libânio C, Nascimento DM, organizadores. Ocupações urbanas na região metropolitana de Belo Horizonte. Belo Horizonte: Favela é isso aí; 2016.

22. Brasil. Ministério da Saúde, Conselho Nacional de Saúde. Resolução nº 466, de 12 de dezembro de 2012. Brasília, DF: Ministério da Saúde; 2012. [acesso em 2020 maio 7]. Disponível em: http://www.conselho. saude.gov.br/resolucoes/2012/Reso466.pdf.
23. Bardin L Análise de conteúdo. São Paulo: Edições 70; 2016.

24. World Health Organization. The Ottawa charter for health promotion: primary Internacional Conference for health promotion. 1986. Ottawa: WHO; 1986.

25. Brasil. Ministério da Saúde; Ministério da Previdência e Assistência Social. $8^{\text {a }}$ Conferência Nacional de Saúde. Brasília, DF: MS; 1986.

26. World Health Organization. Closing the gap in a generation: health equity through action on the social determinants of health: final report of the commission on social determinants of health. Switzerland, Geneva: WHO; 2008.

27. Dias MTF, Calixto JS, Vieira LPO, et al. Ocupações urbanas em Belo Horizonte e a (re)construção espacial da cidade: um estudo de caso da ocupação Camilo Torres. Rev de Ciênc Hum [internet]. 2015 [acesso em 2018 nov 30]; 49(2):205-23. Disponível em: https://periodicos.ufsc.br/index.php/revistacfh/article/view/2178-4582.2015v49n2p205.

28. Passos RA, Nunes SS, Silva LF. A pluralidade do conceito de saúde: o poder de voz dos usuários em uma Conferência Municipal de Saúde. Rev Ciênc Saúde [internet]. 2015 [acesso em 2018 nov 30]; 5(2).91-9. Disponível em: http://186.225.220.234:8484/rcsfmit/ojs2.3.3-3/index.php/rcsfmit_zero/article/view/332/255

29. Lourenço TCB. Cidade ocupada [dissertação]. Belo Horizonte: Universidade Federal de Minas Gerais. Escola de Arquitetura; 2014.

30. Ajlouni MT. Social determinants of health in selected slum areas in Jordan: challenges and policy directions. Int J Health Plann Manage [internet]. 2016 [acesso em 2018 nov 30]; 31(1):113-25. Disponível em: https://www.ncbi.nlm.nih.gov/pubmed/25280236.

31. Martínez-Santos P, Martín-Loeches M, García-Castro N, et al. A survey of domestic wells and pit latrines in rural settlements of Mali: Implications of on-site sanitation on the quality of water supplies. Int J Hyg Environ Health. [internet]. 2017 [acesso em 
2018 nov 30]; 220(7):1179-1189. Disponível em: https://www.ncbi.nlm.nih.gov/pubmed/28807472.

32. Makoge V, Maat H, Vaandrager L, et al. Health-Seeking Behaviour towards Poverty-Related Disease (PRDs): A Qualitative Study of People Living in Camps and on Campuses in Cameroon. PLoS Negl Trop Dis [internet]. 2017 jan [acesso em 2018 nov 30]; 11(1). Disponível em: https://www.ncbi.nlm.nih.gov/ pmc/articles/PMC5214973/.

33. Breilh J. La determinación social de la salud como herramienta hacia una nueva salud pública (salud colectiva). Rev Fac Nac Salud Pública [internet]. 2013 abr [acesso em 2018 nov 30]; 31(supl1):S13-S27. Disponível em: http://www.scielo.org.co/pdf/rfnsp/v31sl/ v31sla02.pdf.

34. Borghi CMSO, Oliveira RM, Sevalho G. Determinação ou determinantes sociais da saúde: texto e contexto na América Latina. Trab educ saúde [internet]. 2018 [acesso em 2018 nov 30]; 16(3):869-897. Disponível em: http://www.scielo.br/scielo.php?script=sci_ arttext\&pid=S1981-77462018000300869\&lng=en\&n $\mathrm{rm}=\mathrm{iso}$.

35. Starfield B. Atenção primária: equilíbrio entre necessidades de saúde, serviços e tecnologia. Brasília, DF: Unesco: Ministério da Saúde; 2002.

36. Donabedian A. An introduction to quality assurance in health care. New York: Oxford University Press; 2003.

37. Albuquerque MSV, Lyra TM, Farias SF, et al. Acessibilidade aos serviços de saúde: uma análise a partir da Atenção Básica em Pernambuco. Saúde debate [internet]. 2014 [acesso em 2018 nov 30]; 38(esp):18294. Disponível em: http://www.scielo.br/pdf/sdeb/ v38nspe/0103-1104-sdeb-38-spe-0182.pdf.

38. Arantes LJ, Shimizu HE, Merchán-Hamann E. Contribuições e desafios da Estratégia Saúde da Família na Atenção Primária à Saúde no Brasil: revisão da literatura. Ciênc. Saúde Colet. 2016; 21(5):1499-1509.
39. Almeida APS, Nunes BP, Duro SMS, et al. Determinantes socioeconômicos do acesso a serviços de saúde em idosos: revisão sistemática. Rev Saúde Pública [internet]. 2017 [acesso em 2018 nov 30]; 51:115. Disponível em: http://www.redalyc.org/articulo. oa?id=67249591054.

40. Brasil. Ministério da Saúde. Redes regionalizadas de atenção à saúde: contexto, premissas, diretrizes gerais, agenda tripartite para discussão e proposta de metodologia para apoio à implementação. Brasília, DF: MS; 2008.

41. Brasil. Ministério da Saúde. Portaria n 4.279 de 30 de dezembro de 2010. Estabelece as diretrizes para a organização da Rede de Atenção à Saúde no âmbito do Sistema Único de Saúde (SUS). Diário Oficial da União. 2010 Dez 30. [acesso em 2020 maio 6]. Disponível em: https://bvsms.saude.gov.br/bvs/saudelegis/gm/2010/prt4279_30_12_2010.html.

42. Brasil. Ministério da Saúde. Política Nacional de Atenção Básica. Brasília, DF: MS; 2012.

43. Faria RM. A atenção primária, o território e as redes de atenção: intercambiamentos necessários para a integração das ações do Sistema Único de Saúde (SUS) em Minas Gerais, Brasil. Rev Brasil de Geog Méd Saúde [internet]. 2014 [acesso em 2018 nov 30]; 10(19):8-23. Disponível em: http://www.seer.ufu.br/ index.php/hygeia.

44. Bezerra ACV, Bitoun J. Metodologia participativa como instrumento para a territorialização das ações da Vigilância em Saúde Ambiental. Ciênc. Saúde Colet. 2017; 22(10):3259-68.

45. Abbott LS, Elliott LT. Eliminating health disparities through action on the social determinants of health: a systematic review of home visiting in the United States, 2005-2015. Public Health Nurs [internet]. 2017 [acesso em 2018 nov 30]; 34(1):2-30. Disponível em: https://www.ncbi.nlm.nih.gov/pubmed/27145717.

46. Nascimento DM. As políticas habitacionais e as ocupações urbanas: dissenso na cidade. Cad Me- 
trop [internet]. 2016 [acesso em 2018 nov 30]; 18(35):145-64. Disponível em: http://www.scielo.br/scielo.php?script=sci_arttext \&pid=S2236$-99962016000100145 \& \operatorname{lng}=\mathrm{en} \& \mathrm{nrm}=$ iso.

47. Chaves L, Alves AC, Souza J, et al. Curso Participação popular, movimentos sociais e direito à saúde: uma experiência de educação popular em saúde na Bahia a partir do Mobiliza SUS. Interface comun saúde educ [internet]. 2015 [acesso em 2018 nov 30]; 18(supl2):1507-12. Disponível em: http://pesquisa.bvs. br/aps/resource/pt/lil-736394.

48. Pohlenz M, Coser K. O estudo do uso e ocupação irregular em áreas de preservação permanente urbanas. Jus Brasil [internet]. 2016 [acesso em 2018 nov 12]; 67(2). Disponível em: https://jus.com.br/ artigos/47822/o-estudo-do-uso-e-ocupacao-irregular-em-areas-de-preservacao-permanente-urbanas.

49. Prado TASZ. Reurbanização da favela do Real Parque em São Paulo: um olhar sobre impactos e possibilidades do processo de reestruturação urbana [tese]. São Paulo: Universidade de São Paulo; 2017.

50. Tobias R, O’Keefe M, Künzle R, et al. Early testing of new sanitation technology for urban slums: the case of the Blue diversion toilet. Sci Total Environ [internet]. 2017 [acesso em 2018 nov 30]; 576:26472. Disponível em: https://www.ncbi.nlm.nih.gov/ pubmed/27788441.

51. Cançado TCL, Souza RS, Cardoso CBS. Trabalhando o conceito de vulnerabilidade social. In: Anais do $19^{\circ}$ Encontro Nacional de Estudos Populacionais; 2014 Nov 24-28; São Pedro. São Paulo: ABEP; 2014.

52. Carmo ME, Guizardi FL. O conceito de vulnerabilidade e seus sentidos para as políticas públicas de saúde e assistência social. Cad. Saúde Pública [internet]. 2018 [acesso em 2018 nov 30]; 34(3):1-14. Disponível em: http://www.scielo.br/scielo.php?script=sci
arttext\&pid=S0102-311X2018000303001\&lng=en\&n $\mathrm{rm}=\mathrm{iso}$.

53. Assumpção EA, Scharmm FR. Bioética e habitação: leitura ética sobre as ocupações urbanas no Rio de Janeiro. Rev Bioé [internet]. 2013 [acesso em 2018 nov 30]; 21(1):96-105. Disponível em: http://www.scielo. br/pdf/bioet/v2lnl/allv2lnl.pdf.

54. Coelho JS. Construindo a Participação Social no SUS: um constante repensar em busca de equidade e transformação. Saúde Soc [internet]. 2012 [acesso em 2018 nov 30]; 21(1):138-51. Disponível em: http://www.scielo.br/pdf/sausoc/v21s1/12.pdf.

55. Pervin A. Some Aspects of Community Empowerment and Resilience. Space Cult, India [internet]. 2015 [acesso em 2018 nov 30]; 3(1):103-6(4). Disponível em: https://scholar.google.com.br/scholar?as_ ylo $=2014 \& \mathrm{q}=$ empowerment + community + developm ent\&hl=pt-BR\&as_sdt=0,5\&as_vis=1.

56. Gohn MG. Pluralidade da representação na América Latina. Soc estado [internet]. 2014 [acesso em 2018 nov 30]; 29(1):73-90. Disponível em: http://www. scielo.br/scielo.php?script=sci_arttext\&pid=S0102$-69922014000100005 \& \operatorname{lng}=$ en\&nrm=iso.

57. Juliano MCC, Yunes MAM. Reflexões sobre rede de apoio social como mecanismo de proteção e promoção da resiliência. Ambient Soc [internet]. 2014 [acesso em 2018 nov 30]; 17(3):135-54. Disponível em: https:// www.researchgate.net/profile/Maria_Yunes/publication/272090966_Reflexes_sobre_rede_de_apoio_social_como_mecanismo_de_proteo_e_promoo_de_resilincia/links/54da69f90cf2ba88a68d2f02.pdf.

\footnotetext{
Recebido em 18/07/2019

Aprovado em 08/04/2020

Conflito de interesses: inexistente

Suporte financeiro: não houve
} 